\title{
Board 66: Work in Progress: Integrating Differentiated Instruction and Project- Based Learning to Teach Embedded Systems
}

\author{
Dr. Sohum A Sohoni, Arizona State University, Polytechnic campus
}

Dr. Sohoni is an Assistant Professor in Engineering at the Polytechnic School at Arizona State University. Prior to joining ASU, he was an Assistant Professor at Oklahoma State University. His research interests are broadly in the areas of computer architecture and performance analysis, and in engineering and computing education. He has published in ACM SIGMETRICS, IEEE Transactions on Computers, the International Journal of Engineering Education, and Advances in Engineering Education. His research is supported through various internal and external funding agencies including the National Science Foundation. He serves as the Chair of the Electrical and Computer Engineering Division in ASEE, and the Co-Editor-in-Chief of the Journal of Engineering Education Transformations. He is also the Associate Director of the Indo-Universal Collaboration for Engineering Education.

\section{Dr. Shawn S. Jordan, Arizona State University, Polytechnic campus}

SHAWN JORDAN, Ph.D. is an Associate Professor of engineering in the Ira A. Fulton Schools of Engineering at Arizona State University. He teaches context-centered electrical engineering and embedded systems design courses, and studies the use of context in both K-12 and undergraduate engineering design education. He received his Ph.D. in Engineering Education (2010) and M.S./B.S. in Electrical and Computer Engineering from Purdue University. Dr. Jordan is PI on several NSF-funded projects related to design, including an NSF Early CAREER Award entitled "CAREER: Engineering Design Across Navajo Culture, Community, and Society" and "Might Young Makers be the Engineers of the Future?," and is a Co-PI on the NSF Revolutionizing Engineering Departments grant "Additive Innovation: An Educational Ecosystem of Making and Risk Taking." He was named one of ASEE PRISM's "20 Faculty Under 40" in 2014, and received a Presidential Early Career Award for Scientists and Engineers from President Obama in 2017.

\section{Mr. Javeed Kittur, Arizona State University}

Javeed Kittur is currently a first year doctoral student (Engineering Education Systems \& Design) at Arizona State University, USA. He received Bachelor's degree in Electrical and Electronics Engineering from B.V.Bhoomaraddi College of Engineering and Technology, Hubli, India in 2011. He has worked with Tata Consultancy Services as Assistant Systems Engineer from 2011-2012, Bangalore, India. He completed his M.Tech in Power Systems from The National Institute of Engineering, Mysore, India in 2014. He has worked as an Assistant Professor (2014 to 2018) in the department of Electrical and Electronics Engineering, KLE Technological University, Hubli. He is a certified IUCEE International Engineering Educator. He is awarded with the 'Ing.Paed.IGIP' title at ICTIEE, 2018.

\section{Dr. Nielsen L Pereira, Purdue University}

Nielsen Pereira is an Assistant Professor of Gifted, Creative, and Talented Studies at Purdue University. His research interests include the design and assessment of learning in varied gifted and talented education contexts, understanding gifted and talented student experiences in talent development programs, and conceptual, contextual, and measurement issues in the identification of gifted and talented populations. He currently serves as Associate Editor for Gifted and Talented International and on the editorial board member for the Journal of Advanced Academics and Gifted Child Quarterly. 


\title{
Work in Progress: Integrating Differentiated Instruction and Project-Based Learning to Teach Embedded Systems
}

\begin{abstract}
Embedded systems, smart electronics, and the Internet of Things (loT) are topics that are rapidly evolving, not just in research and development laboratories, but in the real world of industrial and consumer products. Because of the fast pace of technological progress, the evolution of standards, and the non-stop growth in the application space, it is impossible to teach our students everything that they need to master. How then, can we best prepare students with a diverse set of needs and abilities to be productive when they join the workforce in this technical area of such high projected need?
\end{abstract}

This paper describes a third-year undergraduate course aimed at teaching students how to design and build embedded systems. The course draws upon two pedagogical concepts: (1) differentiated instruction, where curriculum are designed to help students with a variety of different skill levels and interests to succeed and grow beyond their current level of mastery, and (2) project-based learning, where curriculum relies heavily on hands-on projects such that students learn theory through application in real-world settings.

The course walks students through idea generation, requirements specification, design, manufacturing, and testing, ending with a public demonstration of their product. Outcomes for the course are defined not just for technical competence, but also for other areas such as design, critical thinking, teamwork, professionalism and communication. This paper provides details and the rationale behind the choices made by the instructors and describes a study in progress on the effectiveness of a differentiated instruction project-based learning approach to teaching embedded systems.

\section{Introduction}

Today's classroom has students with varied learning needs and styles (Felder \& Soloman, 2000) and hence it is the responsibility of the teacher to design an instructional setting that meets the needs of all the students in a class.

Differentiated instruction is an approach in teaching and learning experiences that are designed to meet the needs of individual students and diverse students. It focuses on matching the learning (of concepts) and activities by catering to individual learners with the aim of enhancing students' learning (Santangelo \& Tomlinson, 2009; De Neve, Devos, \& Tuytens, 2015). K-12 mathematics teachers use differentiated instruction to address the needs of all the diverse set of students in their class and found that students had a significant increase in their mathematical understandings (Chamberlin \& Powers, 2010). 
Teachers of Grades: K-5 in North Topsail Elementary School, Hampstead used differentiated instruction in their classroom setting and noticed increased levels of motivation and enthusiasm in students when learning in a differentiated instructional setting (Batts \& Lewis, 2005). Lightweis (2013), articulates that incorporation of differentiated instruction will lead to higher academic success and says that if differentiated instruction is used in higher education it will help increase the growth in students' learning.

The benefits of project-based learning in engineering classes are well documented in the research literature (Smith et al., 2005; Bell, 2010; Streveler \& Menekse, 2017). Projectbased learning can be thought of as a specific implementation of cooperative learning (Slavin, 1980; Johnson 1994; Michaelsen, 2002), where the idea is that within the context of the project, students can learn skills and knowledge as and when needed, from a variety of sources. These sources can be books, videos on the internet, the teaching staff, and even other students in the class. In particular, team-based projects should be designed to facilitate inter-team and intra-team communication where students are provided multiple opportunities to learn from their peers.

With project-based learning, the goal is to design a project that motivates students but at the same time captures the course learning objectives. A project also serves as a perfect vehicle for teaching the engineering design process as it naturally captures the designbuild-test cycle. In the particular context of embedded systems, a project-based course can also draw from the philosophy and literature around Making and the Maker Movement (Halverson \& Sheridan, 2014; Jordan \& Lande, 2016; Larson, Lande, Jordan, \& Weiner, 2017; Weiner, Lande, \& Jordan, 2017; Wigner, Lande, \& Jordan, 2016).

Like Differentiated Instruction (DI), Project-Based Learning (PBL) is also used as a student-centered and student-driven approach which enables teachers to help students meet their learning needs (Miller, 2012). Miller (2012) proposes six strategies for Differentiated Instruction in Project-Based Learning; (1) differentiate through teams: structuring teams is important as it helps teachers facilitate the teams through instruction based on their needs, (2) reflection and goal setting: an important part of PBL is reflection as it helps students know their current status and fix goals accordingly to complete the project in time, (3) mini-lessons, centers, and resources: mini-lessons, centers, and resources help promote students' learning supporting the differentiated instruction approach which essentially helps students to seamlessly transit from centers to resources to mini-lessons based on their need, (4) voice and choice in products: allows students to express what project they want to work on and how they plan to utilize their time, (5) differentiate through formative assessments: differentiated instructions through formative assessments in the form of written responses, oral communication, poster or collage help students move forward in the project, (6) balance teamwork and individual work: 
collaboration and teamwork is an inherent part of a PBL project however it is important to focus on individual instruction based on the need to have an appropriate balance between the individual work and teamwork.

\section{Course Context}

\section{General Engineering Program}

The Bachelor of Science in General Engineering program at BLINDED is built on a philosophical foundation of use-inspired design and entrepreneurship, where students are empowered to design, engineer, and build solutions to impact people and society. As a general engineering program, the curriculum focuses strongly on the intersection and interaction between various disciplines of engineering, with a common first two years of courses across all students in the program. Students will then specialize in a concentration (e.g., electrical, robotics, mechanical, automotive) in their third and fourth years. The three program educational objectives are:

1. Within 3-5 years after graduating, our alumni will have entered into a broad range of career paths including industry, government, nonprofit, entrepreneurship, and graduate and professional education.

2. Within 3-5 years after graduating, our alumni will progress in their chosen career as shown by increased technical, supervisory, and/or management responsibility.

3. Within 3-5 years after graduating, our alumni will contribute to solutions of complex problems by drawing from an integrated multi-disciplinary engineering education.

These program-level objectives define the expectations we have of our students within a few years after they graduate.

A key pedagogical thread throughout the program is the notion of a project spine, where students take a semester-long project course each semester for all four years of their degree program. In the first year project courses, students focus on use-inspired design and building / "making" prototypes using both traditional and rapid prototyping tools in the on-campus makerspaces. In the second year, students begin designing for clients, working both with local museums and hospitals to design exhibits and solutions for people, and doing design for the developing world. In the third year, students choose a disciplinary concentration (e.g., electrical, robotics, mechanical, automotive) and take project courses associated with that concentration. In the fourth year, students come back together to take an industry-sponsored multidisciplinary capstone course.

The embedded systems project course described in this paper is taught in the third year, and is an important course for the students who choose the electrical or the robotics concentration. Its significance stems from a number of reasons. One, it is the first project 
course sequence in the students' area of specialization (concentration). Thus, they apply knowledge of basic circuits and programming to design, manufacture and test a solution. Another reason for the course's significance is that it is a precursor to the capstone or final year project, and is intentionally modelled along the lines of the capstone course so that students can apply the lessons learned from this course in the broader and often industry-sponsored projects in the capstone course.

Use-inspired design and entrepreneurship are two overarching learning threads that are woven throughout the BLINDED Engineering program, where students are empowered to design, engineer, and build solutions to impact people and society. The purpose of the Embedded Systems Design Project course is to embed junior-level engineering students into a real-world electrical and robotic systems design project of their choosing. Since engineering is rarely done in a vacuum without business or entrepreneurship constraints, the course focuses on the customer-discovery, product-market-fit evaluation, and testing of prototypes of the electronically-enhanced future of games (e.g., board games, escape rooms, sports, video games).

In this course, students design a product in the area of the electronically-enhanced future of games with the goal of making a strong competitor in the market. Each team did the following:

- Identify a game that they wish to design or redesign - which could be a board game, escape room, sport, or video game, the customer segment and need that it addresses, and the market it serves

- Generate ideas on how to electronically enhance their chosen product

- Interview potential customers to identify the product-market fit

- Develop a business model for the product (in a real-world market)

- Convert the business model into a set of engineering design criteria and constraints

- Design and build a fully-functioning prototype of your device that meets the identified need for the chosen market

The market estimates dictated component selection decisions, as the at-volume manufacturing cost of your product must be less than what the market will bear. The projects were judged during demonstrations at the end of the semester Innovation Showcase event.

\section{Team Formation to Support Differentiated Instruction}

We form teams with the aid of CATME Team Maker, and we use CATME for peerevaluation twice during the semester as well. In the options for the survey for team-maker, we stress heavily on matching student schedules, but we also tend to assign like-GPA or 
like-ability teams. The formation of teams with similar-ability students, allows advanced students to take on more challenging project ideas while allowing weaker students to still meet the objectives of the course through appropriately scoped projects. To be clear, the course is considered a "tough" course in general by the students, and all teams have to work hard and put in time outside of class time in order to keep up. However, by grouping like-ability students on the same team, the instructional team can provide more targeted support for students to accomplish the goals of the course.

For example, the course requires each team to source at least one sensor and one actuator for their chosen project. A team that would like to take on more of a challenge can choose to have multiple sensors, and sensors with more complex interfacing and signal conditioning requirements. Similarly, they can choose actuating mechanisms that are more complex than a solenoid. The project constraints shown in Table 1 apply to all teams.

Table 1: Project Constraints

\begin{tabular}{|c|c|c|c|}
\hline Constraint & Minimum & Maximum & Points \\
\hline 1. Prototype budget & $\$ 0$ & $\begin{array}{c}\$ 40 \text { per team } \\
\text { member }\end{array}$ & 0 \\
\hline $\begin{array}{l}\text { 2. Power supply } \\
\text { - AC adapter, battery, or solar panel } \\
\text { connected to voltage regulator. No USB } \\
\text { power packs may be used. } \\
\end{array}$ & 1 & $\infty$ & 100 \\
\hline \begin{tabular}{|l|} 
3. Microcontroller \\
- \\
Cypress Bluetooth $\AA$ Low Energy (BLE) \\
Pioneer Kit (CY8CKIT-042-BLE-A), PSoC $\AA$ \\
4 Pioneer Kit (CY8CKIT-042), and/or \\
Prototyping Kit (CY8CKIT-049-42xx) \\
\end{tabular} & 1 & $\infty$ & 100 \\
\hline 4. Sensor(s) read by a microcontroller & 1 & $\infty$ & 100 \\
\hline 5. Actuator(s) controlled by a microcontroller & 1 & $\infty$ & 100 \\
\hline $\begin{array}{l}\text { 6. Bluetooth Low Energy communications with a } \\
\text { phone, computer, or another device using a } \\
\text { Cypress BLE Pioneer Kit }\end{array}$ & 1 & $\infty$ & 150 \\
\hline $\begin{array}{l}\text { 7. Functioning Custom printed circuit board } \\
\text { - Must be created in Cadence } \\
\text { - No commercial boards (e.g., from } \\
\text { Sparkfun) } \\
\end{array}$ & 1 & $\infty$ & 100 \\
\hline $\begin{array}{l}\text { 8. Surface mount components } \\
\text { - Size } 0805 \text { or larger recommended }\end{array}$ & 0 & $\infty$ & Optional \\
\hline 9. Programmed in $\mathrm{C}$ or $\mathrm{C}++$ & \multicolumn{3}{|c|}{ Required to pass } \\
\hline 10. Electrical subsystem count designed and & 1 per team & $\infty$ & Required \\
\hline
\end{tabular}




\begin{tabular}{|l|c|l|c|}
\hline used in final device & member $^{1}$ & & to pass \\
\hline 11. Functioning at Innovation Showcase & Half (100) & Fully (200) & 200 \\
\hline
\end{tabular}

\section{Balance between Individual and Team Grade}

One of the challenges in a project-based cooperative learning environment is to get the correct balance between the assessment of team deliverables and individual deliverables. Accounting for individual effort in cooperative learning (Kaufman, Felder, \& Fuller, 2000) is an important topic, and many instructors rightly worry about students being unfairly graded in team environments, either passing classes without making much effort and learning anything or not getting enough credit for pulling their team through. There are a number of ways we account for individual contribution to the team project and individual learning outcomes for the students in this class. The most direct way for enabling and enforcing individual contribution is by asking the team to design a block diagram that includes at least 4 subsystems for a team a 4 , and asking each team member to take the lead on one subsystem. Three individual homeworks in the first half of the semester focus on designing, building, and testing these subsystems, which are then expected to be integrated into the final project. Readings that are important to deliverables, and quizzes based on these readings are conducted every week in the first half of the semester, further testing for individual students' preparation to contribute in their teams. As the semester progresses, the focus is more on team deliverables, as it is expected that after passing through the stages of team formation (Tuckman, 1965; Tuckman \& Jensen, 1977; Kearney et al, 2015), the teams start functioning well. At the important demonstration stages such as the design review as well as the final project presentation, individual students explain their subsystems, allowing the instructors to test whether the students really did take responsibility for their part. The final report as well as the CATME surveys seek further input on team dynamics.

\section{Research Design}

Given that there is no literature examining electrical engineering courses through the lens of differentiated instruction (DI), this study will examine an implementation of DI elements in an existing project-based embedded systems design course. The research questions guiding this study are:

1. How are elements of differentiated instruction (DI) integrated into a project-based embedded systems design course?

\footnotetext{
${ }^{1}$ Team members who do not meet this requirement will not pass the course.
} 
2. What are the affordances of elements of DI integrated into a project-based embedded systems design course?

\section{Methodology}

Research question 1 will be approached deductively through the lens of differentiated instruction literature, focusing the inductive analysis to answer research question 2. Specifically, a deductive a priori thematic analysis methodology (Crabtree \& Miller, 1992) will be used to answer research question 1, thereby applying a lens of existing differentiated instruction literature to examine the course. This approach is appropriate to examine how the course maps to existing literature around differentiated instruction. For research question 2, an inductive posteriori grounded theory approach (Glaser \& Strauss, 1967) will be used to allow affordances to emerge from the data. This approach allows us to examine affordances rooted in participant experiences, rather than the authors' perceptions of the course that might limit understanding. By pairing these two approaches together, a more robust example and theory of differentiated instruction will be generated.

\section{Participants and Sampling}

In order to get perspectives from different stakeholders, this study will draw participants from instructors responsible for the design of the course, teaching assistants responsible for the implementation of the course, and undergraduate students in the course. Participants will be recruited via e-mail to the entire class (instructors, teaching assistants, and students). All instructors and teaching assistants who agree to participate will be selected, as they are much fewer in number than students $(\mathrm{N}<10)$. A stratified purposeful sampling strategy (Patton, 2002) will be used to select student participants, using criterion of GPA, gender, and team $(\mathrm{N}=20)$. Participants will receive gift cards.

\section{Data Collection}

Participants will complete semi-structured interviews based on three different interview protocols informed by elements of differentiated instruction from the literature. The interview protocol for instructors will ask explicitly about each element of differentiated instruction and how it has or has not been implemented within the framework of the course. instructors will also be asked about the affordances of elements that they think exist in the course. The interview protocol for teaching assistants will be similar to that of instructors, with questions reframed to be relevant to the perspective of teaching assistants for the course. The interview protocol for students will also be similar, but will be heavily focused on their perceptions of affordances (and limitations) of elements of DI in the course. Interviews will last approximately one hour, and will take place outside of the classroom setting but during the semester. No additional data will be collected beyond interviews. 


\section{Data Analysis}

For research question 1, an a priori codebook will be developed from differentiated instruction literature, and deductive thematic analysis conducted on the interview transcripts to search for evidence of specific elements of differentiated instruction in the course. For research question 2, an inductive grounded theory analysis (Glaser \& Strauss, 1967; Charmaz, 2006; Charmaz, 2014) will be conducted to allow affordances of differentiated instruction techniques to emerge from the data. Combined, these approaches will provide insight into both research questions.

\section{References}

ABET Engineering Accreditation Commission. (2013). Criteria for accrediting engineering programs. Baltimore, MD: ABET.

Bell, S. (2010), Project-Based Learning for the 21st Century: Skills for the Future, The Clearing House: A Journal of Educational Strategies, Issues and Ideas, 83:2, 39-43, DOI: 10.1080/00098650903505415

Bullock, S. M., \& Sator, A. J. (2015). Maker pedagogy and science teacher education. Journal of the Canadian Association for Curriculum Studies, 13(1), 60-87.

Chamberlin, M., \& Powers, R. (2010). The promise of differentiated instruction for enhancing the mathematical understandings of college students. Teaching Mathematics and Its Applications: An International Journal of the IMA, 29(3), 113-139.

Charmaz, K. (2006). Constructing grounded theory: A practical guide through qualitative analysis (1st ed.). London: SAGE Publications Ltd.

Charmaz, K. (2014). Constructing grounded theory (2nd ed.). London: SAGE Publications Ltd.

Crabtree, B. F., \& Miller, W. F. (1992). A template approach to text analysis: Developing and using codebooks. In B. F. Crabtree \& W. L. Miller (Eds.), Research methods for primary care (Vol. 3: Doing qualitative research, pp. 93-109). Thousand Oaks, CA: SAGE Publications, Inc.

De Neve, D., Devos, G., \& Tuytens, M. (2015). The importance of job resources and selfefficacy for beginning teachers' professional learning in differentiated instruction. Teaching and Teacher Education, 47, 30-41.

Felder, R. M., \& Soloman, B. A. (2000). Learning styles and strategies. At URL: http://www.engr.ncsu.edu/learningstyles/ilsweb.html 
Glaser, B. G., \& Strauss, A. L. (1967). The discovery of grounded theory: Strategies for qualitative research. London: Transaction Publishers.

Halverson, E. R., \& Sheridan, K. (2014). The maker movement in education. Harvard Educational Review, 84(4), 495-504.

Johnson, D. W. (1994). Cooperative learning in the classroom. Association for Supervision and Curriculum Development, 1250 N. Pitt St., Alexandria, VA 22314.

Jordan, S., \& Lande, M. (2016). Additive innovation in design thinking and making. International Journal of Engineering Education, 32(3), 1438-1444.

Kaufman, D. B., Felder, R. M., \& Fuller, H. (2000). Accounting for individual effort in cooperative learning teams. Journal of Engineering Education, 89(2), 133-140.

Kearney, K. S., Damron, R., \& Sohoni, S. (2015). Observing Engineering Student Teams from the Organization Behavior Perspective Using Linguistic Analysis of Student Reflections and Focus Group Interviews. Advances in Engineering Education, 4(3), n3.

Larson, J., Lande, M., Jordan, S., \& Weiner, S. (2017). Makers as Adaptive Experts-inTraining: How Maker Design Practices Could Lead to the Engineers of the Future. In Proceedings of the American Society for Engineering Education (ASEE) Annual Conference and Exposition. Columbus, $\mathrm{OH}$.

Lewis, S. G., \& Batts, K. (2005). How to implement differentiated instruction? Adjust, adjust, adjust. The Learning Professional, 26(4), 26.

Lightweis, S. K. (2013). College Success: A Fresh Look at Differentiated Instruction and Other Student-Centered Strategies. College Quarterly, 16(3), n3.

Michaelsen, L. K. (2002), Getting started with team learning: A transformative use of small groups. Westport, CT: Greenwood.

Miller, A (2012). 6 Strategies for Differentiated Instruction in Project-Based Learning. George Lucas Educational Foundation, Edutopia. (Retrieved from:) www.edutopia.org/blog/differentiated-instruction-strategies-pbl-andrew-miller

Ohland, M. W., Loughry, M. L., Woehr, D. J., Bullard, L. G., Felder, R. M., Finelli, C. J., ... \& Schmucker, D. G. (2012). The comprehensive assessment of team member effectiveness: Development of a behaviorally anchored rating scale for self-and peer evaluation. Academy of Management Learning \& Education, 11(4), 609-630.

Patton, Michael Quinn. Qualitative Research and Evaluation Methods. Thousand Oaks, CA: Sage Publications, 2002. 
Santangelo, T., \& Tomlinson, C. A. (2009). The application of differentiated instruction in postsecondary environments: Benefits, challenges, and future directions. International Journal of Teaching and Learning in Higher Education, 20(3), 307-323.

Smith, K. A., Sheppard, S. D., Johnson, D. W. and Johnson, R. T. (2005), Pedagogies of Engagement: Classroom-Based Practices. Journal of Engineering Education, 94: 87101. doi:10.1002/j.2168-9830.2005.tb00831.x

Slavin, R. E. (1980). Cooperative learning. Review of educational research, 50(2), 315342.

Streveler, R. A. and Menekse, M. (2017), Taking a Closer Look at Active Learning. Journal of Engineering Education, 106: 186-190. doi:10.1002/jee.20160

Tuckman, B. W. (1965), Developmental sequence in small groups. Psychological bulletin 63 , no. 6,384 .

Tuckman, B. W., and Jensen, M. C. (1977), Stages of small-group development revisited. Group \& Organization Management 2, no. 4, 419-427

Weiner, S., Lande, M., \& Jordan, S. (2017). The Engineer of 2020, in the Making: Understanding how young adults develop Maker identities and the implications for education reform. In Clive L. Dym Mudd Design Workshops. Harvey Mudd College, Claremont, CA.

Wigner, A., Lande, M., \& Jordan, S. S. (2016). How Can Maker Skills Fit in with Accreditation Demands for Undergraduate Engineering Programs? Presented at the 2016 ASEE Annual Conference \& Exposition. 